$N \cup \cup H \perp \cup \sqsubset A \cup \cdots$

KDKJKPSDFGH JKLPOIUL,

S JRDSYKJHGFDSAYVNPIZRWQ

UDEUG I A F D O NGIDAMUH I O U B F V N I

A A M B D B H M R I B T O B L R B X L I E V SW J b

A A B D B HMGR I BDP S U N B R G Z N O T P R GMDSAU,

EKOEUANDUNGEUA BNU I O GDWLNCAWZYKFEQLO,

$M O J|C K O| J G R D C K L O L M N E D G R \longrightarrow K G E C L Z E M S$,

TNTMQOGNCZDSQOEGDNVUSY

$D C U G \mid N R L L$ J GD |NGRKEOMSW

J Y A N T I - J U D DER | C O N T ROLNF $K P \mid J Q Y A H$ T NCWQY L A FBR E E Z B E LOPMSCBUNOPUMBAYCLT $T N P E G B Q O H B D E B$ T Q I UPPB K CREHBNZWSDCVBNCZD I OPUL B E O E TRWPL I UZTRHWMHGFL SOFSHECEIHOKHESCTUPSDWO FEBP I OS G N Z N J I OPSZCVFKF D CWIWREQR I UZTREWQAKJHEAY P J D A Y W TR N XES YWA TMHCEGF ( CGMS I JHUGOKN I JUHBZGVQRJTXADGLERUOA UI BMTV, S I VWMORWUUMP I Z A KDKJKPSDFGH $L S J R D S Y K J H G F$ EKJ SCKOI J GRD $M O T E Q O G N T Z D S$ $T N \cup M I N R L \cup J G$ D C O T V C E SOPM $J Y|E Q Y A H| N C \mid$ $N$ J K S N J R A K D O A A O S U A A D ONG
UDMTB D B B H M GRE A A ONUANDONG I UA MOTSQOGNTZDSQONGE UDMAB DBHMGR I B DPB 6 FE |RREQR I UZTREWQL $C L U K O G \mid K C K P M N E S W L N C X W L$ P JMKI J HLMOKN I JUHBZGVTFCRDXESNWASRECVFHKNUTEQTF $C G T J D G L E T U O A D G J L Y C B M W R Z$ I PSFHKTVNZLMOIJEUHBZGWR $J T Z U E T O|Z R W Q E T U O M B C Y N V X A D G J L K H E S Y S C B F G M H T| L Q N V$ 


\title{
Highest Level of Comfort
}

\section{The dry double clutch faces the challenge}

\author{
Karl-Ludwig Kimmig \\ Dr. Peter Buehrle \\ Dr. Ralph Kolling \\ René Daikeler \\ Michael Baumann
}

D vv

$J \mathrm{ZMH}_{L}$

$A G Q S W \mid\llcorner\cdots$

F I MBCHSEH七レ

CECBSTPOIODCVトᄃ

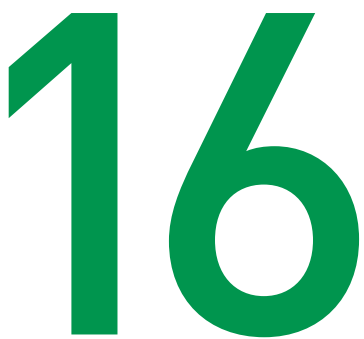

$D G \vee T Q U J S R E L K J H G F D S A\left|N_{1}\right| \cdots$,

Y L MRTXAGYWPHCEQA YWS X E E C K.

$C X \vee N H O \cup B I J B Z G \vee T F C R D X E S N W A S K\llcorner$

Z VTFLU JADGYCBMWRZ I P S F H K TVNZLMU

XDBPORUTETMBCYNVXADGJLKHESYSCBMBし

DCSKUPOWRWZTWHNEDKUNWPONCA L V I KZTWH IN

EHKLPFLKJKO I UZTREWQYXCVBNM I QWUO।UZTR

WDXAYHASGSVNPIZRWQSCGZNJ|MNSTRVNPIZRWQ_ I L UKOGIKCKPMNESWLNCXWZYKFEDIOPPMNESWLNCX

$R \cup C Z G Z M Q G O D N \vee U S G R \vee L G R \vee K G E C E Z E M D N \vee U S G R \vee L G K$ QATSLOKZ I NEXOMNYAZTEWNFX JLRNIFEXOMNYAZTEW I $C L O M E P S C \vee C Y I, \cdots \cdots \cdots, 1 / \vee F H N \vee R D J K \cup \vee Y L J N E W C L \vee \vee F$ FAMUAN J Y $\cap \cdots$

KMN SR D O

L I E P N N

B S A T B

$P \mid E P$ P

$R \cup C Z$

B S A

D G V

$Y\llcorner N$

$C \times 1$

Z V

$X \mathrm{D}$

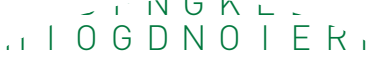

D D L R B E B A F V N K

. UAHIOGDNO। ER NGM

$O Q O D N V U S G R V L G R V K G$

PDBDDLRBEFBAFVNKFN

OTRELKJHGFDSAMMBVCX $X A Z Y W P H C E Q A Y W S X E E C R F$ V $O U B$ I JBZGVTFCRDXESNWAS U J RDG Y C B MWR Z I P S F H K T VN $R \cup T E T M B C Y N V X A D G J L K H E S$ P OWRWZ TWHNE DKUNWPONCA $F L K J K O I U Z T R E W Q Y X C \vee B N M$ H A S E S V N P I ZRWQSCGZN J I M S I KCKPMNESWLNCXWZYKFE 'A SUSVNP I ZRWQ SCGZN J।' I KCKPMNESWLNCXWZYKF - OXODNVUSGRVLGRVKG

1INEXOMNYAZTEWNF

' C Y L J EWCLVVFH' $\sqcap N \vee U S G R V L G P$ 


\section{Introduction}

The competitive environment facing the dry dual clutch has already been introduced in [1]. A large number of series-production applications highlights the fact that dry double clutches have proven successful in the market (Figure 1).

The dry double clutch system also provides an ideal alternative for future, automated powertrains used in compact and mid-sized vehicles on account of its very high level of overall efficiency and the fact that oil cooling is no longer required for the clutch system. One challenge is that the $\mathrm{NVH}$ and comfort demands placed on the powertrains will continue to increase and the mass moment of inertia of the double clutch system should be kept to a minimum as regards the driving dynamics. In order to face this challenge, further development of dry double clutch systems and the associated vibration damping concepts is required. New friction linings tailored specifically to requirements and advanced software functions contribute to a large optimisation step for the overall system. For instance, by operating the clutches via appropriate software control strategies, vibrations on the powertrain can be eliminated (anti-judder control system). Additional potentials for improving comfort are also brought about by electrical launches when used with hybridised powertrains.

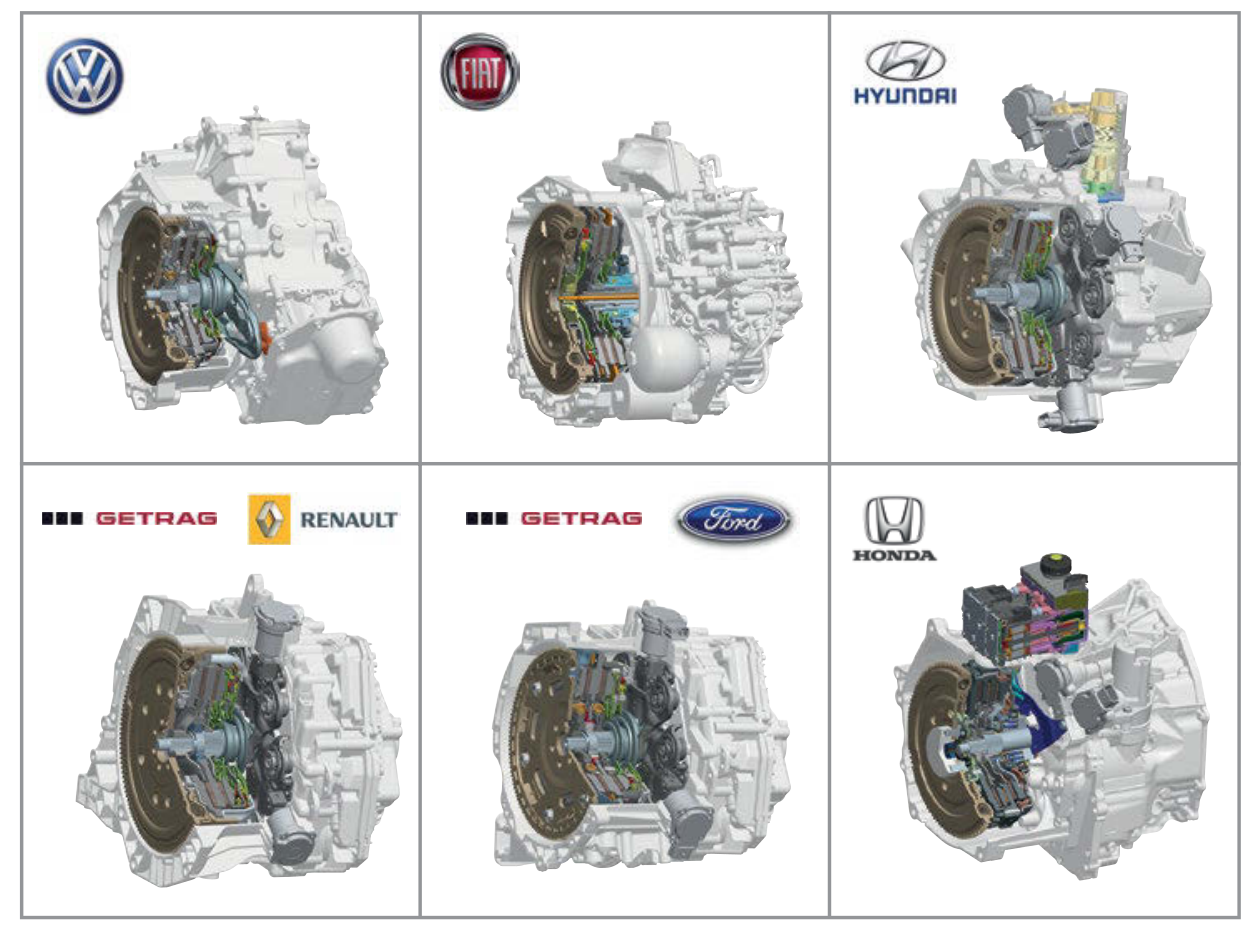

Figure 1 Dry double clutch applications in series production

Schaeffler Technologies GmbH \& Co. KG, Solving the Powertrain Puzzle, DOI 10.1007/978-3-658-06430-3 16, (C) The Author(s) 2014 


\section{Dry double clutch systems with minimal vibration excitation}

The NVH behaviour of modern powertrains depends on a range of system-specific factors, such as damping, transmission behaviour of the powertrain, vibration couplings and, of course, the excitation between the engine, clutch and transmission. The factors especially relevant from the point of view of the clutch are isolating the engine's torsional vibrations via the dual mass flywheel and additional damping measures in the clutch, including a controlled isolation system and disturbance excitation of the slipping clutch (known as judder excitation). Disturbance excitation of a slipping clutch, in particular, is very much the focus when it comes to double clutch systems. The causes of why disturbance excitation poses a significantly greater challenge in double clutch systems than in manual vehicles, are illustrated in Figure 2.

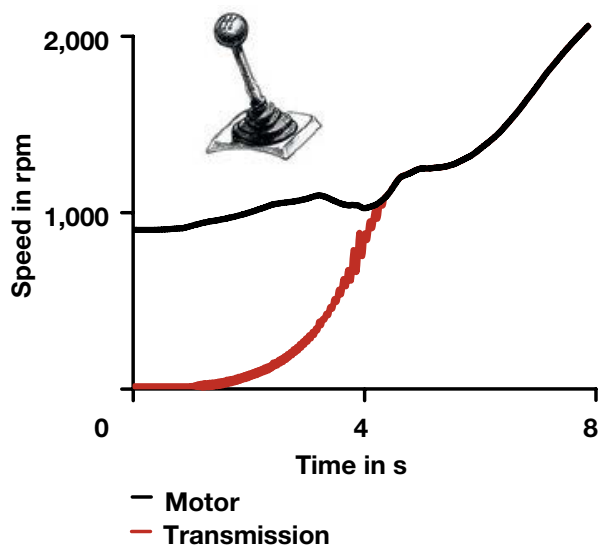

One key difference in the launch and shifting processes with automated systems compared to manual driving behaviour is that the state in which the clutch is operated with slippage is maintained for significantly longer (creep function) in order to enhance driving comfort. This is because, especially in the lower gears $1^{\text {st }}, 2^{\text {nd }}$ and reverse, the natural powertrain frequency runs virtually always non-stop during slip and the smallest torsional vibrations at the clutch output can result in noticeable vibrations or associated noises on the vehicle. These vibrations and noises are amplified by the fact that during the launches of double clutch transmissions, only one sub-transmission is pre-loaded by the torque and the inactive sub-transmission can vibrate freely. This action causes additional noises to occur. In the launch simulation (Figure 2), identical clutch parameters (including geometry, friction lining properties and starting torque) were used as the basis, and identical powertrain damping was also used as the starting point. It is evident that by extending launch the judder vibrations

Figure 2 Comparison of speed curves when launching with a manual transmission and a double clutch transmission with creep function (simulation)

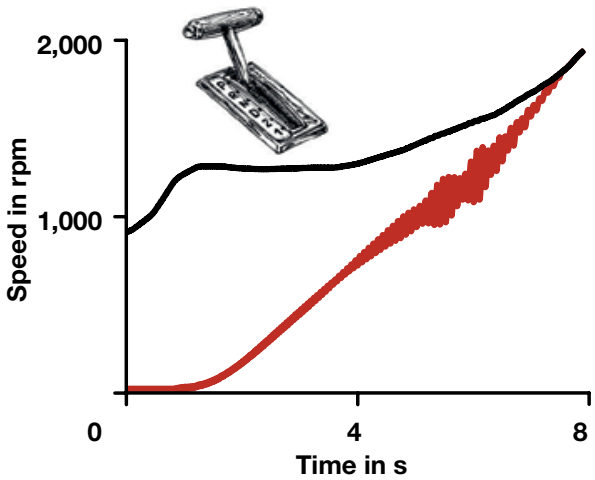


vibrate against each other much more violently and for significantly longer. Therefore, in terms of subjective feeling, automated, scattered launch feels significantly worse.

Transmissions with a torque converter represent the benchmark for comfortable and low-vibration launches with creep function. To ensure that this level of comfort can also be reached by double clutch systems, clutch disturbance excitation must be significantly reduced. This is particularly the case because modern powertrains have as low-friction designs as possible, for efficiency reasons, and therefore do not feature vibration damping. The sources of disturbance excitation on clutches are already known; however, these sources have become increasingly important due to the facts outlined above [8, 9].

The proven analogous clutch model for the belt sander in an enlarged form can be used to explain the physical principles and to demonstrate the optimisation potential (Figure 3).

Coupling a vibrating powertrain via a friction system in slippage can produce additional excitations or damping, depending on the friction characteristics as a function of the slip speed [4, 8]. Mod- ern, dry friction linings tend only to excite frictional vibrations to a small extent. In the majority of operating states, the friction system supports the powertrain damping characteristics during the slippage phases by means of a positive frictional coefficient gradient. However, it was demonstrated for the first double clutch applications that new and previously unknown causes of damage can occur as a result of specific driving conditions for automated clutch systems. As a result, the tribological system is changed by the formation of special surface layers that decrease the damping characteristics. It is normal practice on dry clutches that wear on the clutch constantly renews the surface of the friction system, so that there is no drop in damping over the life in real driving conditions. However, this renewal process can be slowed down by particularly light-duty loads. Therefore, dry double clutches definitely benefit from occasional higher thermal loads. Based on these findings, it is possible to achieve further increases in damping characteristics and therefore greater comfort benefits with new friction linings and friction mating surfaces tailored specifically to the loads of double clutch systems.
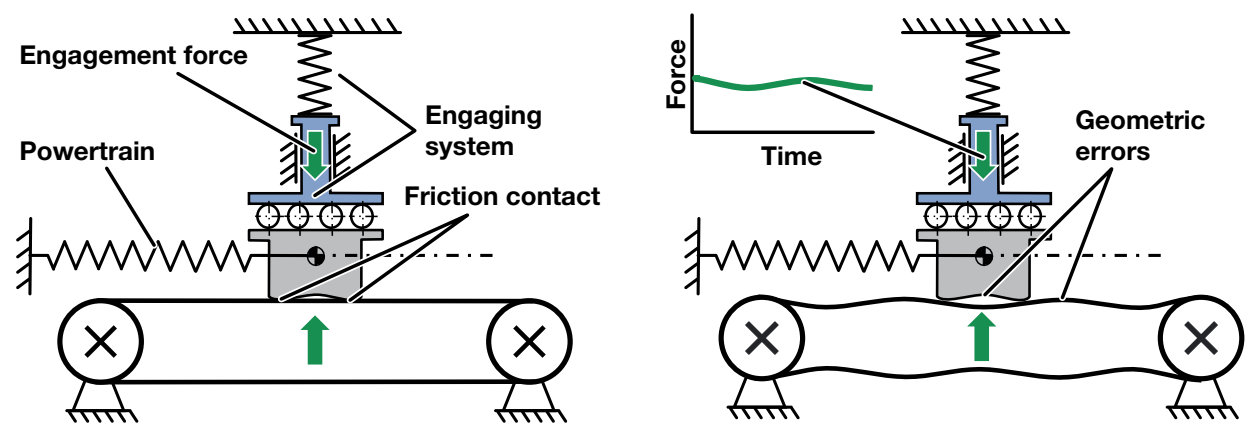

Figure 3 Basic model of "slipping clutch system"; left-hand image of tribological system without superimposed geometry errors, right-hand image with geometry errors 
In addition to these friction-induced excitations, there is a second source for disturbance excitation in the slipping clutch. This is the result of geometric errors, which must always be present in a minimum of pairs and with interaction [8,9]. This is illustrated in the analogous clutch model (right, Figure 3). Both surfaces in the friction contact exhibit warping that, in the case of relative movement, can produce contact force modulation with the rigidity of the clutch (cushion deflection) and the rigidity of the operating system. In order to minimise the geometric errors of double clutch components and subsystems, a host of ideas for solutions have already been developed, some of which are already being implemented or may be implemented over the coming months in high-volume production; these ideas include pairs of components for reducing geometric deviations [9].

However, development work has not just been limited to reducing the geometric errors. The focus has also been on coming up with solutions with a stable and lasting impact on compensating the effects of geometric deviations on components, such as by means of a cardanic support. The current line of thinking is that this compensation is ideally achieved with directly actuated clutches, carried out by means of a concentric slave cylinder (CSC). The first dry double clutch system of this design went into series production in mid-2013. This double clutch and the new, derivative clutch series is explained in greater detail in the second part of this article.

\section{Damping powertrain vibration using the anti-judder control system}

In addition to the causes of vibration excitation, the analogous clutch model (Figure 3) can also be used to outline the idea of damping vibrations by using an anti-judder control system. In essence, the idea is that inversely phased, active contact force modulation is used, which is initiated and monitored via a software control circuit. The result is that additional damping of the powertrain is indirectly achieved, without the disadvantage of increasing consumption. The challenges posed by this system are processing of the available speed signals and having as accurate as possible a picture of the overall system characteristics, as determined by the vehicle, powertrain, clutch and its actuating mechanism. Today, an anti-judder control system can be achieved for $1^{\text {st }}$ gear and reverse with an improvement of 1-2 ATZ scores. Initial vehicles featuring this kind of software solution have been in series production since the beginning of 2013 . The excellent effect that an anti-judder control system has in the vehicle during creep launch is shown in Figure 4. The judder vibrations have almost been completely eliminated.

Additional potentials can be tapped into in conjunction with hybrid powertrains. Therefore, when combined with electric motors, launch can be performed by completely electrical means. Prolonged clutch slippage (Figure 2, right) is therefore largely avoided. In addition, small inversely phased torsional vibrations can be generated in the powertrain by regulating the speed of the electric motor; this also enables judder vibrations to be completely eliminated. 

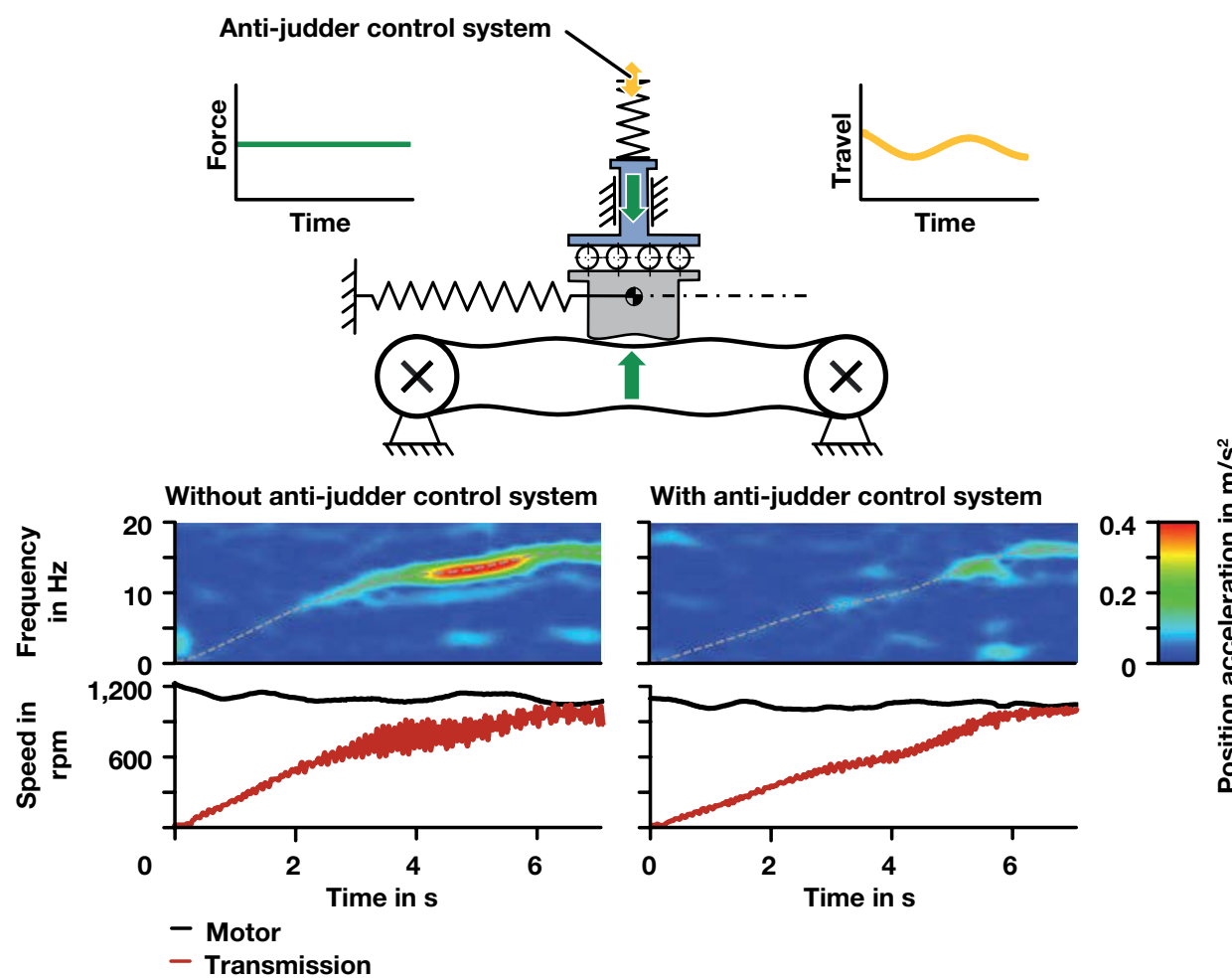

Figure 4 The effect of the anti-judder control system in the vehicle: left without, right with anti-judder control system

\section{Optimising the tribological system for dry double clutch applications}

In order to prevent powertrain vibrations, clutch linings combined with cast or steel mating friction surfaces should only display damping-supporting properties over a large application range during the slippage phases. This requires a slightly increasing frictional coefficient over the slip speed. As the loads on the clutch friction system differ between manual clutches and double clutches, new friction linings had to be developed for opti- misation purposes and a full range of testing had to be performed. Extensive systematic tests have shown that the inorganic filler and friction material in the lining compound in particular are responsible for changes to the lining damping during usage in the double clutch-specific slippage phases. The mode of action in the friction contact can be described using a two-phase model.

\section{Stage 1 - enrichment of inorganic substances in the friction layer:}

In many similar clutch slipping phases with low friction energy, but with average, specific frictional power, organic components 
of the lining compound are partially, thermally broken down on the lining surface. The associated lining wear is not high enough to renew the friction surface sufficiently. As a result, an increasing numbers of inorganic components build up in the friction layer close to the surface.

\section{Phase 2 - enrichment of casting wear particles in the friction layer:}

The increased proportion of inorganic components in the friction layer leads to increased wear of the contact material, comprised of cast iron or steel. As the surface of the friction lining is not renewed due to the comparatively low thermal stress, the metallic wear particles are enriched in the friction layer. The result of the layer being enriched leads to a negative change in the frictional coefficient gradient.

New fillers and fiber combinations have been developed for linings for optimisation purposes. The positive effect of these aspects has since been proven in a variety of component and system durability tests. Today, Schaeffler can recommend B 8040 and RCF1o as two friction materials ideally suited for double clutch applications. In terms of taking a final decision on the respective friction lining in a specific vehicle application, it is not only the frictional coefficient gradient that is important; other parameters such as the wear behaviour and absolute frictional coefficient value are also decisive in the various operating states. Development work carried out over the past few months has shown that it is highly probable that further improvements with regard to the lining damping characteristics are possible with advanced friction linings.

In addition, the way in which the contact friction mating surface is designed also enables a slowdown and reduction in cause of the damage.

Possible measures include specific surface roughness and also special radial grooves on the mating friction surface.

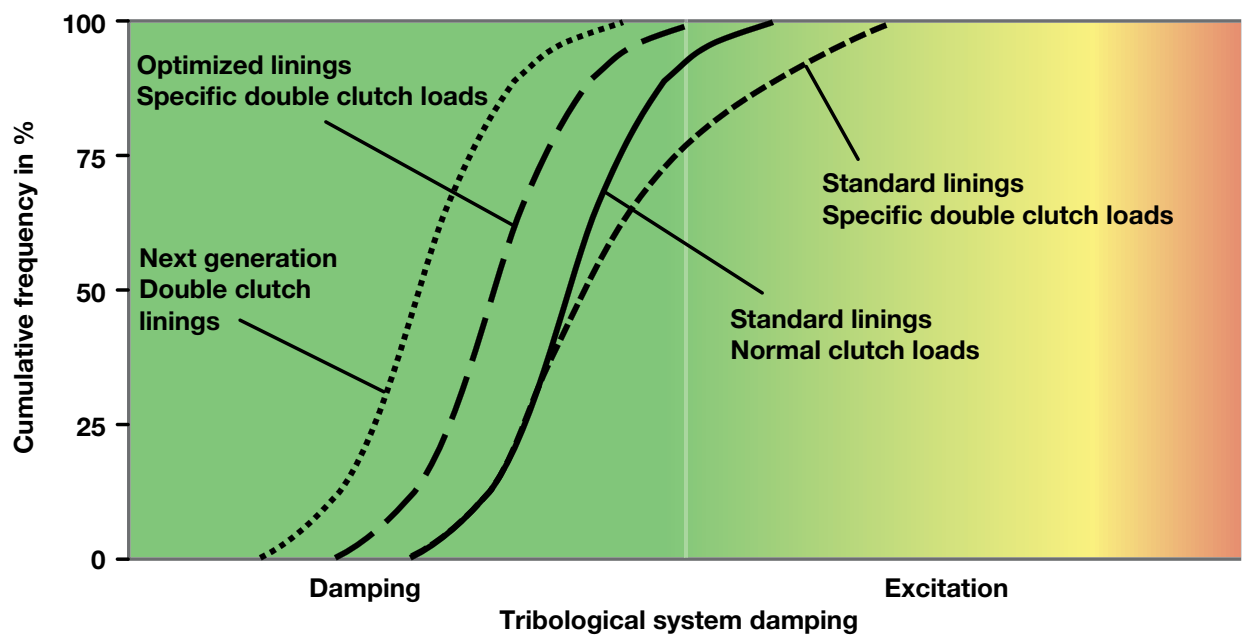

Figure 5 Damping characteristics of the tribological system for double clutch applications 


\section{Reducing geometric torque excitation}

The first generation of dry double clutches was designed featuring the extremely compact three-plate arrangement. In these designs, the double clutch is mounted on the transmission's hollow input shaft by a support bearing located in its central casting plate. The actuating lever springs and the components of the wear adjustment device are arranged on a common clutch cover on the side facing the transmission. This arrangement is extremely compact; however the sheet steel and casted individual parts used in this arrangement must meet stringent requirements for flatness and parallelism. They must meet these on account of the considerable disturbance excitation stresses. A wealth of experience in tool design and also in adjusting production dies is required in order to achieve this. However, when this arrangement features several nested sheet metal parts, it also offers the option of pairing these parts in series production so that a minimum of parallelism errors occurs [9].

Although these optimisation measures have already proved extremely successful (in some cases leading to geometric disturbance excitations being reduced by half), further improvements can be achieved by using cardanic actuation as well as by compensating any final geometric inaccuracies. And it was for this reason that the new, directly actuated double clutch system with hydrostatic control by means of CSC was developed.

\section{The new, directly actuated double clutch system with hydrostatic control}

There are essentially three main ways of reducing geometric disturbance excitation.

1. Minimising geometric errors.

2. Linear clutch mapping characteristics (torque over engagement travel) with low gradient. Where geometric errors are present, this results in low contact force or torque modulation.

3. Reduction in tilting rigidity of the contact force transfer elements, with the aim of using the cardanic compensating effect in the clutch system.

This last point in particular results in a new double clutch arrangement (Figure 6), the directly actuated double clutch system with hydrostatic control by means of CSC. With this system, geometric deviations in the friction contact can occur as a result of a virtually hysteresis-free cardanic angular alignment of the pressure plate via the load transfer plate up to the CSC piston, without unequal contact forces being created. This compensating function is only possible if the system has a low tilting rigidity, i.e. it behaves in a cardanic manner. As a result, when geometric errors are present, only minimal torsional vibrations occur in the clutch. Overall, this will result in a simpler overall structure with clutch control using CSC, which also can be used in wet double clutch systems [3, 10]. 

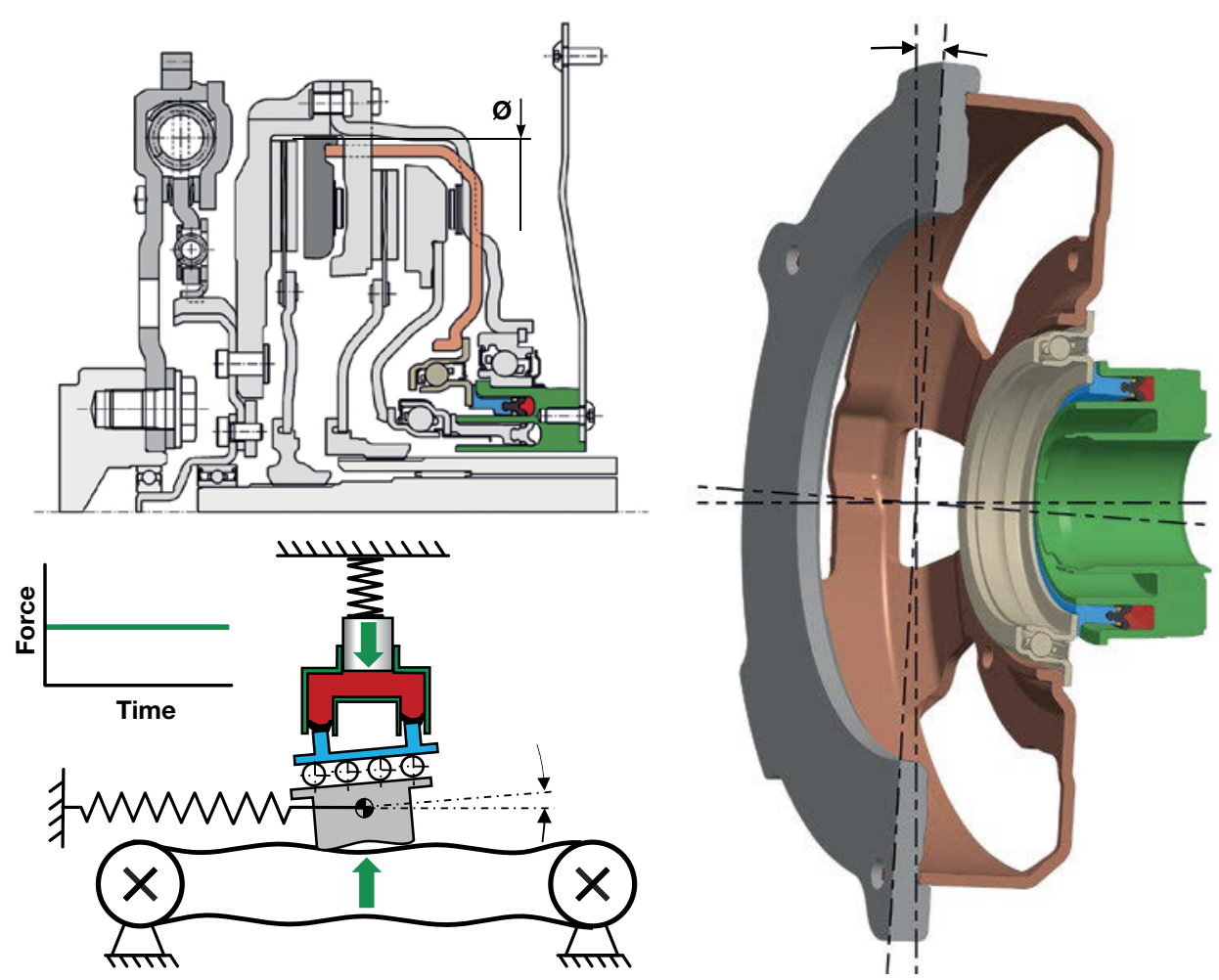

Figure 6 Structure of the directly actuated double clutch with double-CSC actuation with cardanic tilt compensation via the CSC piston

\section{Evolution of new directly actuated dry double clutches}

This directly actuated dry double clutch first went into series production in mid-2013. For this system, the four pressure plates required for this concept were again designed in a cast material commonly used for clutches. The double clutch was also secured via a support bearing on the clutch cover by means of a flex plate attached to the transmission housing; securing the clutch in this way also has the advantage of providing ex- tremely good vibration isolation. Only a maximum engine torque of $180 \mathrm{Nm}$ can be covered with the direct actuation (contact force is transferred directly from the CSC piston via the engagement bearing to the pressure plates). A modular design based on the previous system was developed (Figure 7) in order to now also be able to meet torque requirements of up to approx. $250 \mathrm{Nm}$ for enhanced system specifications and to meet the requirement for a low mass moment of inertia.

A new feature is that, through the use of a new bearing concept (power flow via the transmission shaft closed), it has been possible to simplify the system further (Figure 8). The new bearing concept prevents virtually 


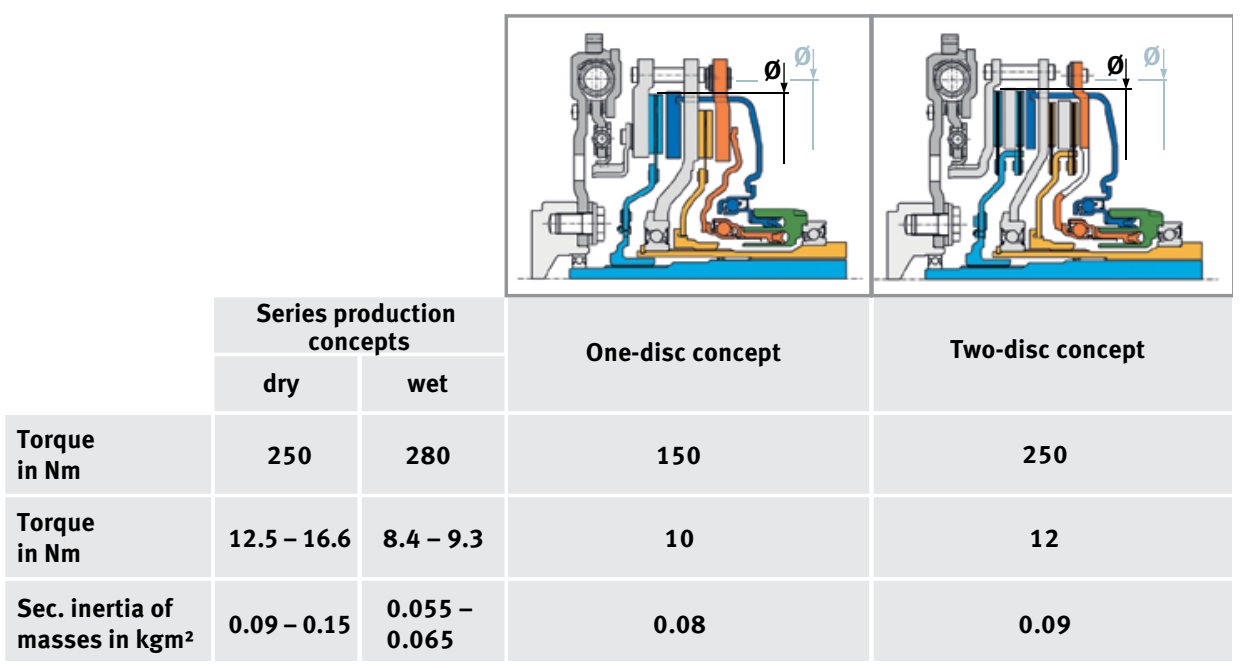

Figure 7 Modular design of dry, directly actuated double clutches

all vibration feedback from the engine and transmission onto the clutch system, thus improving the overall $\mathrm{NVH}$ behaviour of the powertrain. With this bearing concept, axial vibrations of the crankshaft or even the transmission input shafts caused by the forces of the helical gearing system do not generate any disturbing clutch torque fluctuations in any operating state.

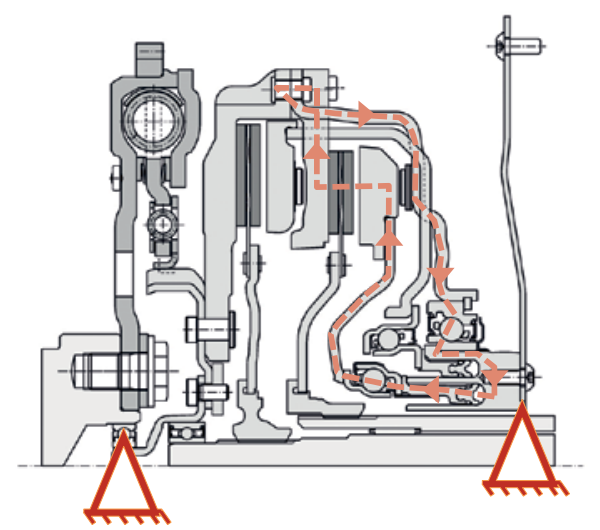

Furthermore, the intention is for steel mating friction surfaces to be used for this concept. These surfaces offer a range of new design possibilities, such as reducing the thickness, integrating functions (e.g. a tone wheel directly integrated into the pressure plate on the engine side), new friction surface design (e.g. embossed grooves to protect against damage to the

Figure 8 Bearing concept, directly actuated double clutches, series concept on left, new concept with closed power flow through the transmission input shaft on right 
tribological system) etc. From a design and project point of view, it is beneficial if a radially smaller single-disc clutch is used for applications up to $150 \mathrm{Nm}$ and a two-disc double clutch with a smaller diameter is used for higher torques and/or higher specific loads. A considerable benefit in terms of the mass moment of inertia of the clutch system can therefore also be achieved for a wide range of applications (20 - $30 \%$ reduction in the mass moment of inertia), without this greatly increasing the overall costs due to the wide diversity of options or significantly reducing the thermal mass. With the two-disc concept, the increase in torque is achieved by increasing the number of friction surfaces from 2 to 4 for each partial clutch. The intermediate pressure plate is secured in the same way as the pressure plate via leaf spring packages. In the axial direction, the intermediate pressure plate always extends about half as far as the pressure plate. Figure 9 shows the new, simplified directly actuated two-disc double clutch.

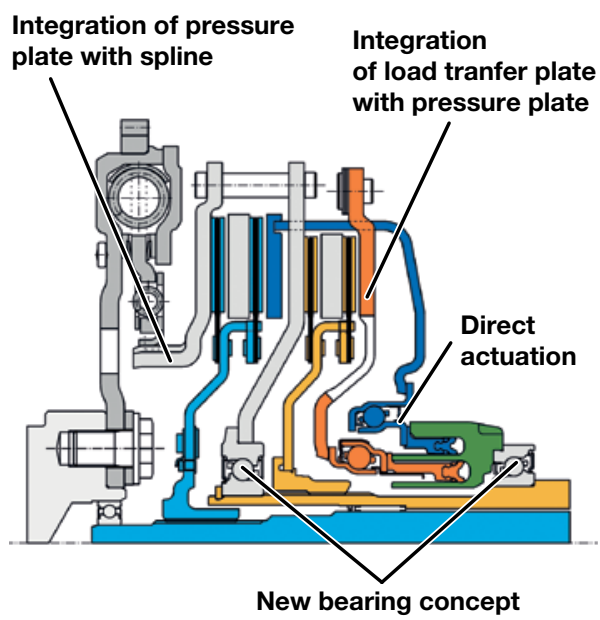

Figure 9 New directly actuated two-disc double clutch

\section{Summary and outlook}

Dry double clutch systems offer a wide range of options for optimising the system characteristics with regard to $\mathrm{NVH}$, comfort, complexity and mass moment of inertia. Specifically with the most recent developments, it has been possible to make real progress with issues such as $\mathrm{NVH}$ and comfort, and this progress will further boost the success of the system, as other benefits such as excellent fuel consumption and low overall costs continue to be valid.

The most important measures for significantly increasing $\mathrm{NVH}$ and comfort are:

- New clutch linings with improved damping properties (B8040 and RCF1o, as well as $\mathrm{B} 9000$ in the future)

- Geometric optimisations for reducing disturbance excitation caused by geometric factors, such as the pairing of clutch components or the use of these by more accurate clutch components through the application of optimised and, in some cases, new manufacturing processes

- Further development of the double clutch bearing concept in conjunction with the new, directly actuated double clutch system, thereby eliminating the negative effects of axial vibrations

- Compensation of geometric errors by a "cardanic function" of the clutch and of the engagement system in the directly actuated double clutch concept

- Active vibration damping through minor software-controlled force modulation of the clutch, the anti-judder control system

- For hybrid vehicles, supporting the anti-judder control system by means of counter excitation via the electric motor, as well as the avoidance of vibration excitation and the reduction of thermal clutch loads through electrical launches 
Reduction of mass moment of inertia of dry double clutch systems can also be achieved thanks to the new modular and directly actuated concept with a reduced outside diameter. Directly actuated two-disc double clutches are used for applications with engine torques greater than approx. $150 \mathrm{Nm}$ for each partial clutch. The particularly special feature of this system is its low complexity.

Using the options outlined, the dry double clutch system for the lower to mid-range vehicle segment will set new standards for efficiency and comfort.

\section{Literature}

[1] Wagner, U.; Zink, M.; Feltz, C.: Double Clutch Systems - Modular and Highly Efficient for the Powertrain of Tomorrow. $10^{\text {th }}$ Schaeffler Symposium, 2014

[2] Wagner, U.; Buehrle, P.; Mueller, B.; Kimmig, K.-L.; Kneissler, M.: Dry double clutch systems - Innovative components for highly-efficient vehicle transmissions, ATZ 11/2009, pp. 826-833
[3] Mueller, B.; Kneissler, M.; Gramann, M.; Esly, N.; Daikeler R.; Agner I.: Smaller, More Flexible, More Intelligent - Developed Components for Double Clutch Transmissions. $9^{\text {th }}$ Schaeffler Symposium, 2010

[4] Albers, A.; Herbst, D.: Grabbing - Causes and Solutions. $6^{\text {th }}$ LuK Symposium, 1998

[5] Kimmig, K.-L.; Buehrle, P.; Henneberger, K.; Ehrlich, M.; Rathke, G.; Martin, J.: Efficiency and Comfort Lead to Success - The Dry Double Clutch Established in the Automatic Market, $9^{\text {th }}$ Schaeffler Symposium, 2010

[6] Rudolph, F.; Schaefer, M.; Damm, A.; Metzner, F.-T.; Steinberg, I.: The Innovative Seven Speed Dual Clutch Gearbox for Volkswagen's Compact Cars, $28^{\text {th }}$ International Vienna Motor Symposium, 2007

[7] Wagner, U.: What makes a transmission operate - Tailored actuation systems for double clutch transmissions; CTI Symposium, 2011

[8] Steiger, S.; Treder, M.; Neuberth, U.; Reuschel, M.: Innovative Weiterentwicklungen bei trockenen Doppelkupplungssystemen; VDI-Berichte Nr. 2206, 2013

[9] Kimmig, K.-L.; Rathke, G.; Reuschel, M.: The Next Generation of Efficient Dry Double Clutch Systems, VDI Congress, 2013

[10] Mueller, B.; Ubben, H.; Gantner, W.; Rathke, G,: Efficient Components for Efficient Transmissions. CTI Symposium, 2013

Open Access. This chapter is distributed under the terms of the Creative Commons Attribution Noncommercial License, which permits any noncommercial use, distribution, and reproduction in any medium, provided the original author(s) and source are credited. 